\title{
Research on Tax Burden and Industrial Structure Optimization of Guangdong Province
}

\author{
Yang Feng \\ Jinan University, Guangzhou, China \\ Email:448106275@qq.com
}

Received 14 January 2016; accepted 18 February 2016; published 24 February 2016

Copyright (C) 2016 by author and Scientific Research Publishing Inc.

This work is licensed under the Creative Commons Attribution International License (CC BY).

http://creativecommons.org/licenses/by/4.0/

(c) () Open Access

\begin{abstract}
Reasonable tax burden level is of great significance to the industrial structure adjustment. Based on current situation of industrial structure and industry tax in Guangdong province, we use econometric analysis method with the level coefficient of industrial structure, analyze the relationship between tax burden and industrial structure and put forward reasonable tax burden of industries in Guangdong province and policy recommendations to promote the upgrading of industrial structure.
\end{abstract}

\section{Keywords}

Tax Burden, The Level Coefficient of Industrial Structure, Optimization and Upgrading

\section{Introduction}

The new normal of economy in our country, which works as the basic situation in the present and the future of economic society, means the moderate slowing-down in economic growth, relatively balanced economic structure, industrial structure transformation and upgrading at the same time and the realization of the industrial structure optimization. Industrial structure optimization means adjustment on the existing industrial structure, taxation is a tool of the realization of government macro-control and is also a measure of market efficient allocation of resources [1]. The tax burden is the core issue of tax policy and system for it affects not only the state concentrated financial resources and macro-control ability, but also the tax burden of enterprises and residents.

During the $12^{\text {th }}$ Five-year Plan, special economic zones of Guangdong vigorously promote independent innovation and continuous optimization and upgrading of industrial structure. However, industrial structure problems 
are still outstanding, such as that industrial structure deviation is obvious, secondary industry quality is not high and the development of modern service industry is insufficient. Therefore, having a good understanding of the interaction between industrial structure optimization and tax burden will be very important for accelerating the process of optimization and upgrading of industrial structure and the realization of rapid economic development in Guangdong province.

\section{Industrial Structure Present Situation of Guangdong}

The development of the secondary and tertiary industry of Guangdong has experienced two stages, namely rapid growth stage from 1993 to 2002 and the fast growth stage since 2003. The growth of primary industry is slow, which widens the gap with GDP of secondary and tertiary industry, and the proportion of primary industry in GDP is falling. According to China Statistical Yearbook, GDP of primary, secondary and tertiary industry of Guangdong province in 1993 were 55.8 billion yuan, 170.4 billion yuan and 120.5 billion yuan, the ratio of added value was 16:49:25, while in 2014 the industry GDP were 316.68 billion yuan, 3.14 trillion yuan and 3.32 trillion yuan, the ratio was 4.7:46.3:49. The proportion of primary industry has an $11 \%$ drop, the proportion of tertiary industry has a $24 \%$ rise and the proportion of secondary industry maintains a relatively stable state.

According to Table 1, industrial structure of Guangdong province in recent years is that the proportion of primary industry remains unchanged, the proportion of secondary industry has a gradual decline and the proportion of tertiary industry is gradually increasing. In 2013, GDP of Guangdong province was 6.22 trillion yuan, the ratio of industrial added value was 4.9:47.3:47.8, and the proportion of tertiary industry firstly transcended the proportion of secondary industry, which has a important significance.

Analyzing from growth rate of industry (as Figure 1), the growth rate of each industry presents a fluctuation change, individual year changes a lot and even has a negative growth. What is more: Growth rate of the primary industry changes most and sometimes it closes to zero growth even has a negative growth. On the one hand, it has something to do with our economic and social background, on the other hand, in recent years more and more attention is given to agriculture, rural areas and farmers' problems, the agricultural tax was cancelled and a series of policies benefiting the farmers were issued, which further consolidated the foundation of agriculture status. At the same time, the growth rate of secondary industry maintains more than $10 \%$ except of 1999 and 2009, but it slows down markedly in recent years, the growth will continue to drag on overall economic performance. While the growth rate of tertiary industry is relatively stable, it is $11.9 \%$ in 2014 and its sustainable growth will continually pull the economy of Guangdong province.

Recent years, industrial structure problems are still outstanding in Guangdong province for two aspects; one is the obvious industrial structure deviation. With economic growth, industrial structure is optimizing gradually but still lags behind the level of GDP. According to the per capita GDP standard, the economic development pattern

Table 1. Change of the industrial GDP and the proportion in Guangdong province a hundred million, \%.

\begin{tabular}{|c|c|c|c|c|c|c|c|}
\hline Year & GDP & $\begin{array}{c}\text { Primary } \\
\text { industry GDP }\end{array}$ & $\begin{array}{c}\text { Secondary } \\
\text { industry GDP }\end{array}$ & $\begin{array}{c}\text { Tertiary } \\
\text { industry GDP }\end{array}$ & $\begin{array}{l}\text { Primary industry } \\
\text { proportion }\end{array}$ & $\begin{array}{l}\text { Secondary industry } \\
\text { proportion }\end{array}$ & $\begin{array}{c}\text { Tertiary industry } \\
\text { proportion }\end{array}$ \\
\hline 2003 & 15844.63 & 1072.91 & 7592.78 & 7178.94 & 6.8 & 47.9 & 45.3 \\
\hline 2004 & 18864.62 & 1219.84 & 9280.73 & 8364.05 & 6.5 & 49.2 & 44.3 \\
\hline 2005 & 22557.37 & 1428.27 & 11356.6 & 9772.5 & 6.3 & 50.4 & 43.3 \\
\hline 2006 & 26587.76 & 1532.17 & 13469.77 & 11585.82 & 5.8 & 50.6 & 43.6 \\
\hline 2007 & 31777.01 & 1695.57 & 16004.61 & 14076.83 & 5.3 & 50.4 & 44.3 \\
\hline 2008 & 36796.71 & 1973.05 & 18502.2 & 16321.46 & 5.4 & 50.3 & 44.3 \\
\hline 2009 & 39482.56 & 2010.27 & 19419.7 & 18052.59 & 5.1 & 49.2 & 45.7 \\
\hline 2010 & 46013.06 & 2286.98 & 23014.53 & 20711.55 & 5 & 50 & 45 \\
\hline 2011 & 53210.28 & 2665.2 & 26447.38 & 24097.7 & 5 & 49.7 & 45.3 \\
\hline 2012 & 57067.92 & 2847.26 & 27700.97 & 26519.69 & 5 & 48.5 & 46.5 \\
\hline 2013 & 62163.97 & 3047.51 & 29427.49 & 29688.97 & 4.9 & 47.3 & 47.8 \\
\hline
\end{tabular}

Data source: China Statistical Yearbook. 


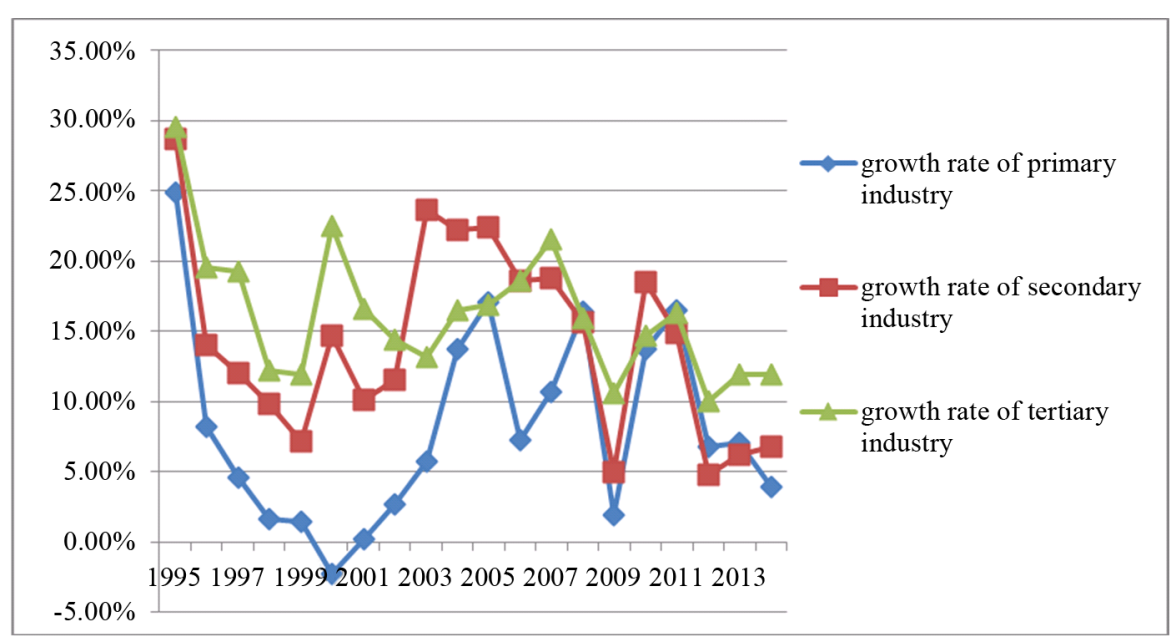

Figure 1. Growth rate of industrial GDP in Guangdong province during 1995 to 2014.

has reached the level of developed country in Guangdong province, but the industrial structure level is far from developed countries [2]. The other one is that industry internal structure is not reasonable, the secondary industry quality is not high, the development of modern service industry is insufficient. The second industry internal structure is not harmonious, the level of industrial structure is low and technological innovation ability is weak, which are the focus of industry transformation; the proportion of the tertiary industry in Guangdong province is increasing, but it focuses on the low-end labor-intensive industries, while modern service industry development is obviously insufficient, so it is unable to meet the needs of the primary and secondary industry development.

\section{Analysis of Industrial Tax Revenue Situation in Guangdong Province}

\subsection{Aggregate Analysis}

Since the $21^{\text {st }}$ century, Guangdong province makes full use of its own advantages to develop economy, GDP continues to grow, especially the industry and service industry have made great achievements, which provides stable tax revenue to Guangdong province.

We can see from Figure 2, the primary industry tax revenue is very low, its trend line is a straight line close to the $\mathrm{X}$ axis compared with the other two lines, and we can't see any changes. Tax revenue mainly comes from the secondary and tertiary industry, and there is an upward trend in them. The secondary industry tax revenue increased from 98.74 billion yuan in 2003 to 472.46 billion yuan in 2013, totally increased 4.8 times, the average annual growth is more than 35 billion yuan. While the tertiary industry tax revenue increased 4.6 times during this period. so we draw the following conclusions: firstly, the primary industry makes little contribution to tax revenue of Guangdong due to abolishment of agricultural tax; secondly, industry, service industry tax revenue is rising fast for many reasons such as the rising GDP, continuous improvement of the tax system and the collection process [3]; thirdly, service industry tax amounts more than industry tax since 2010, and the gap is gradually widening.

\subsection{Structural Analysis}

Industrial tax contribution and industrial GDP contribution do not match, which is the main problem of the industry tax structure in Guangdong province. We can analyze industry tax revenue structure of Guangdong from 2003 to 2012 from Table 2, and draw the following conclusions:

1) From the proportion, primary industry share maintains at $0.1 \%$ level, and there is no large fluctuation. Due to the favorable policies to agriculture in recent years and exemption of agricultural tax, the agricultural tax burden reduces. Continuous optimization of tax structure, gradually it forms a situation which gives priority to the secondary industry and the tertiary industry. The tertiary industry tax revenue increases year by year, with the improvement of economy and industry structure in Guangdong province, tax from the tertiary industry will become the main source of tax revenue, which fits the trend we encourage the development of the tertiary industry. 


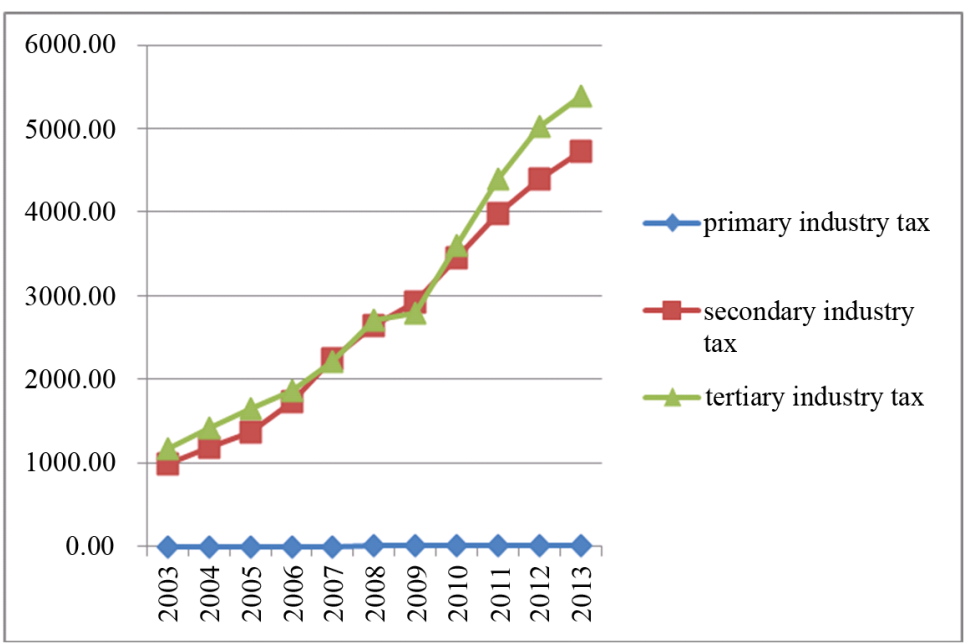

Figure 2. Industrial tax position of Guangdong from 2003 to 2013.

At the same time, high degree of opening to the outside world and the innovation ability of Guangdong are also important reasons.

2) Since 2003, tax burden of secondary industry and tertiary industry and the overall tax burden are rising year by year. Tax burden of the secondary industry rises from 13\% in 2003 to $15.9 \%$ in 2012, up nearly 3\%, tax burden of the tertiary industry rises from $16.4 \%$ in 2003 to $19 \%$ in 2012, up 2.6\%, and the total tax burden rises from $13.65 \%$ in 2003 to $16.5 \%$ in 2012, up $2.85 \%$.

We can see from Figure 3, the primary industry tax burden is far lower than the overall tax burden, while the tertiary industry tax burden is higher than the overall tax burden, and the rapid economic growth of tertiary industry has a lot to do with it. It also illustrates that the support to the tertiary industry tax is not enough in Guangdong, and tax burden will become an important factor restricting the development of the tertiary industry in Guangdong.

\section{Relationship Analysis between Industrial Tax Burden and Industrial Structure}

For further research on relationship between tax burden and upgrade of industrial structure, we select data of industrial output value and tax burden from 2003 to 2013 in Guangdong province (Table 1 and Table 2), use the econometric analysis and answer the interactive relationship.

\subsection{Design of Variables and Model}

We choose the level coefficient of industrial structure as an index to measure industrial upgrading. here we define the level coefficient of industrial structure as, if the regional economy is divided into $\mathrm{n}$ industry, we arrange these industry from high level to low level, and the proportion of these industry notes: $q(j)(0<q(j)<1)$, so we can get the level coefficient of industrial structure of this region [4]:

$$
W=\sum_{i=1}^{n} \sum_{j=1}^{1} q(j)
$$

This equation is actually a weighted sum, obviously higher $\mathrm{W}$ value means the greater level of industrial structure in the region, the opposite is lower. In theory, minimum value of $W$ is 1 , the maximum is $n$. The level coefficient of industrial structure of a region or a country will gradually increase with the development of society and economy and the constant optimization and upgrading of industrial structure, close to 3 . In Figure 4, the level coefficient of industrial structure of Guangdong from 2003 to 2013 is relatively stable and has a small upward trend in recent years.

In Figure 4 we can see that the secondary industry tax burden line and the level coefficient of industrial structure line are basically the same. In 2003-2005 it was on the decline and reached the lowest point in 2005, after that they had a slow upward trend; While the primary and tertiary industry tax burden level line have no 


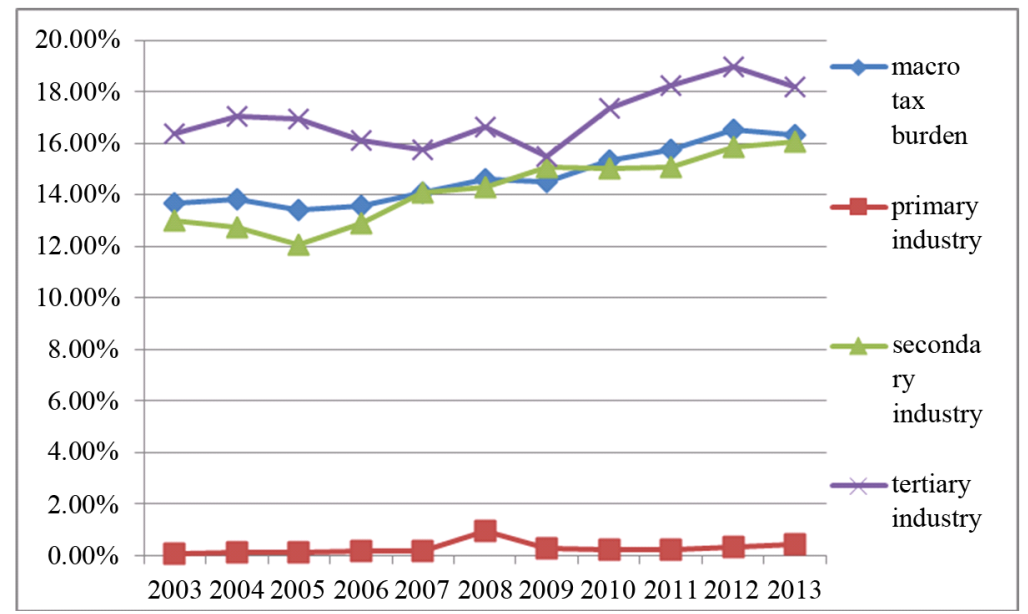

Figure 3. Industrial tax burden position from 2003 to 2012.

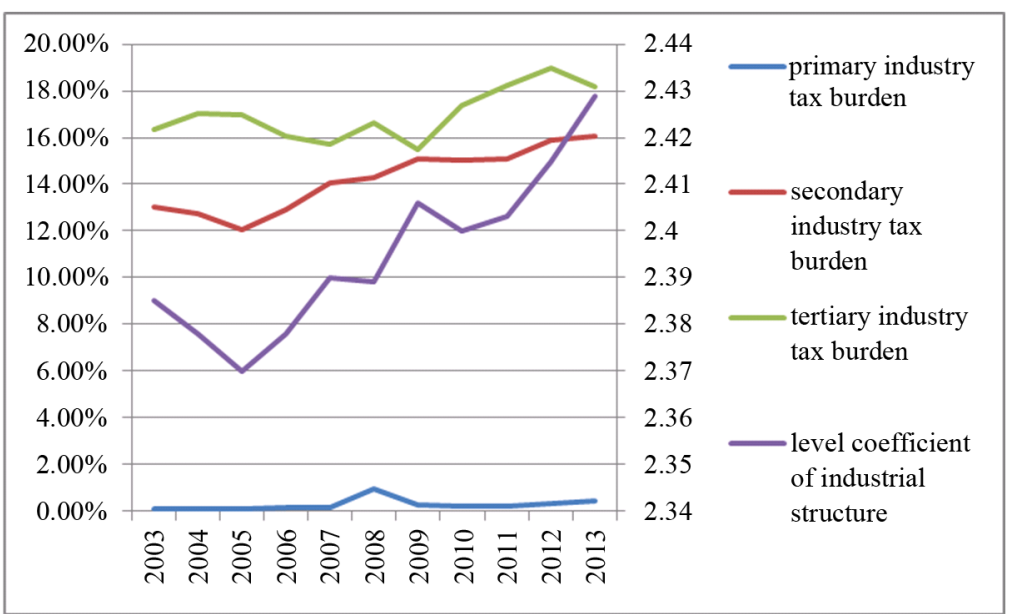

Figure 4. The level coefficient of industrial structure of Guangdong.

Table 2. Industrial tax position from 2003 to 2012.

\begin{tabular}{|c|c|c|c|c|c|c|c|c|c|}
\hline \multirow[b]{2}{*}{ Year } & \multicolumn{3}{|c|}{ Primary industry } & \multicolumn{3}{|c|}{ Secondary industry } & \multicolumn{3}{|c|}{ Tertiary industry } \\
\hline & $\begin{array}{c}\text { Tax } \\
\text { revenue }\end{array}$ & Proportion & $\begin{array}{c}\text { Burden of } \\
\text { taxation }\end{array}$ & $\begin{array}{c}\text { Tax } \\
\text { revenue }\end{array}$ & Proportion & $\begin{array}{c}\text { Burden of } \\
\text { taxation }\end{array}$ & $\begin{array}{c}\text { Tax } \\
\text { revenue }\end{array}$ & Proportion & $\begin{array}{c}\text { Burden of } \\
\text { taxation }\end{array}$ \\
\hline 2003 & 0.9 & $0.0 \%$ & $0.1 \%$ & 987.4 & $45.7 \%$ & $13.0 \%$ & 1174.6 & $54.3 \%$ & $16.4 \%$ \\
\hline 2004 & 1.1 & $0.0 \%$ & $0.1 \%$ & 1181.2 & $45.3 \%$ & $12.7 \%$ & 1425.4 & $54.7 \%$ & $17.0 \%$ \\
\hline 2005 & 1.4 & $0.0 \%$ & $0.1 \%$ & 1368.4 & $45.2 \%$ & $12.0 \%$ & 1657.3 & $54.7 \%$ & $17.0 \%$ \\
\hline 2006 & 2.4 & $0.1 \%$ & $0.2 \%$ & 1737.4 & $48.2 \%$ & $12.9 \%$ & 1863.8 & $51.7 \%$ & $16.1 \%$ \\
\hline 2007 & 2.7 & $0.1 \%$ & $0.2 \%$ & 2253.6 & $50.4 \%$ & $14.1 \%$ & 2215.4 & $49.5 \%$ & $15.7 \%$ \\
\hline 2008 & 18.3 & $0.3 \%$ & $0.9 \%$ & 2645.2 & $49.2 \%$ & $14.3 \%$ & 2715.8 & $50.5 \%$ & $16.6 \%$ \\
\hline 2009 & 5.0 & $0.1 \%$ & $0.2 \%$ & 2926.0 & $51.1 \%$ & $15.1 \%$ & 2795.5 & $48.8 \%$ & $15.5 \%$ \\
\hline 2010 & 5.3 & $0.1 \%$ & $0.2 \%$ & 3457.3 & $49.0 \%$ & $15.0 \%$ & 3598.7 & $51.0 \%$ & $17.4 \%$ \\
\hline 2011 & 6.2 & $0.1 \%$ & $0.2 \%$ & 3988.2 & $47.6 \%$ & $15.1 \%$ & 4392.1 & $52.4 \%$ & $18.2 \%$ \\
\hline 2012 & 9.9 & $0.1 \%$ & $0.3 \%$ & 4397.5 & $46.6 \%$ & $15.9 \%$ & 5031.4 & $53.3 \%$ & $19.0 \%$ \\
\hline
\end{tabular}

Data source: The Chinese Tax Yearbook. 
obvious regularity with the level coefficient of industrial structure.

In order to further analyze the interaction between tax burden and optimization and adjustment of industrial structure, we choose the level coefficient of industrial structure $(W)$ as explained variable and the primary industry tax burden $\left(X_{1}\right)$, secondary industry tax burden $\left(X_{2}\right)$, tertiary industry tax burden $\left(X_{3}\right)$ as explaining variable to make a linear regression. In order to eliminate possible heteroscedasticity, we take logarithm to variable and get the following model:

$$
\ln (W)=c+\beta_{1} \ln X_{1}+\beta_{2} \ln X_{2}+\beta_{3} \ln X_{3} .
$$

\subsection{Data Checking}

Here we use the ADF test for unit root test, comparing the critical value (5\%) with ADF test value. If test value is greater than $5 \%$, which indicates that the original data has unit root and is non-stationary; if the test value is less than $5 \%$, which indicates that the original data has no unit root, and the sequence is smooth. By the test, data is stationary time series, so we can use original data to analyze the next step.

\subsection{The Empirical Results and Analysis}

Now we substitute data into the equation and get regression equation:

$$
\ln W=1.0329-0.0015 \ln X_{1}+0.0779 \ln X_{2}+0.0093 \ln X_{3} .
$$

We can see from Figure 5, coefficient of determination $\mathrm{R}^{2}$ equals to 0.977 , DW equals to 1.346 , which means that the credibility of using Industry tax burden to explain the level coefficient of industrial structure is as high as $92.5 \%$, and the model does not exist autocorrelation; The probability coefficient of $X_{2}$ is 0.0004 , which shows that the regression equation is established, under the $5 \%$ level, the secondary industry tax burden's influence on the level coefficient of industrial structure is significant, but the probability coefficient of $X_{1}$ and $X_{3}$ is big, which shows that the primary and tertiary industry tax burden's influence is not significant. According to the positive and negative of the variable coefficient, it can be explained that secondary industry tax burden and level coefficient of industrial structure are significant positive correlation. The results further confirm that reasonable tax burden contributes to optimization and upgrading of industrial structure of Guangdong.

\section{Conclusions and Suggestions}

The results above show that: the improvement of level coefficient of industrial structure which means upgrading of industrial structure has something to do with secondary industry tax burden. According to the principle of reasonable tax burden, the rise of secondary industry tax burden has its rationality associated with its share of GDP. However, the tertiary industry tax revenue rises fast but there is no significant impact on the upgrading of industrial structure, which means the tertiary industry tax system is not perfect and the phenomenon such as double taxation exists. Therefore, in order to reasonably define the industrial tax burden level of Guangdong and

Sample: 20032013

Included observations: 11

\begin{tabular}{lrlrr}
\hline \hline \multicolumn{1}{c}{ Variable } & Coefficient & Std. Error & t-Statistic & Prob. \\
\hline \hline C & 1.032873 & 0.022575 & 45.75309 & 0.0000 \\
LNX1 & -0.001512 & 0.001479 & -1.022386 & 0.3406 \\
LNX2 & 0.077871 & 0.012225 & 6.369586 & 0.0004 \\
LNX3 & 0.009343 & 0.013502 & 0.691980 & 0.5112 \\
\hline \hline R-squared & 0.925258 & Mean dependent var & 0.873283 \\
Adjusted R-squared & 0.893225 & S.D. dependent var & 0.007376 \\
S.E. of regression & 0.002410 & Akaike info criterion & -8.943043 \\
Sum squared resid & $4.07 \mathrm{E}-05$ & Schwarz criterion & -8.798354 \\
Log likelihood & 53.18674 & Hannan-Quinn criter. & -9.034250 \\
F-statistic & 28.88498 & Durbin-Watson stat & 1.345741 \\
Prob(F-statistic) & 0.000258 & &
\end{tabular}

Figure 5. The level coefficient of industrial structure of Guangdong. 
promote the optimization and upgrading of industrial structure, we should give full attention to the tax policy and consider mainly the following aspects.

1) The local government should make use of the preferential tax policy to vigorously develop agriculture. In recent years, farmers' tax burden of Guangdong reduces unceasingly, but for the urban rural dual system structure urban and rural economic gap remains large. Therefore, the government should increase the intensity of financial reorganization, put an end to the phenomenon of excessive fees and relieve the burden of farmers; In terms of turnover tax, the government should give maximum support to agriculture, make full use of the agricultural tax preferential policies [5] [6]. The government also should increase financial input to the agricultural infrastructure construction, encourage innovation and comprehensively promote the transformation of agriculture.

2) The government should rely on innovation to promote transformation and upgrading of the secondary industry in Guangdong. Guangdong has a very strong industry, but in the face of the ever-changing science and technology and the fierce market competition, Guangdong province must encourage the development of high and new technology enterprise by a series of tax policies to enhance market competitiveness. It's suggested that local government makes full use of tax breaks for corporate r\&d to improve enterprise r\&d enthusiasm and makes full use of the advantage of rich talent from institutes in Guangdong to establish high level tax intermediary service organization which can carry on the tax planning for the enterprise, thus increasing the disposable capital. What's more, local taxation department can establish incentive tax policy to develop the forces of human capital for promoting industrial transformation and upgrading in Guangdong.

3) The government should promote the development of modern service industry by regulating the tertiary industrial tax, improve the efficiency of management of tax authorities by regulating the behavior of tax personnel and give more support to the focus of modern service industry by more preferential tax policies [7]. In addition, the government should actively promote "business tax to added-value tax" work, reduce the industry tax burden, bring the financial sector, real estate and other modern service industry as soon as possible into the scope; and by setting reasonable value-added tax rates and preferential tax policies, the government should further reduce the tertiary industry tax burden level in order to stimulate economic growth potential.

\section{References}

[1] Yuan, G.R. (2004) Fiscal Policy to Promote Industrial Structure Adjustment. China Financial and Economic Publishing House, Beijing.

[2] Guo, Q.W. and Lv, Bi.Y. (2004) Economic Growth and Industrial Structure Adjustment's Impact on Revenue Growth. International Taxation in China, No. 9, 15-16.

[3] Chen, S.Z. (2014) The Path Selection of Industrial Structure Upgrading for Guangdong Coastal Economic Belt in the Post-Crisis Era. Contemporary Economy \& Management, No. 6, 76-82.

[4] Ouyang, H.S., Chen, Y. and Yang, F. (2015) The Tax Burden, Industrial Upgrading and Influence. Modern Finance and Economics, No. 1.

[5] Zhang, S.C. (2010) China’s Strategic Emerging Industry Development and Fiscal Policy. Economic Science Press, Beijing.

[6] An, T.F. (2006) Tax Burden and Tax Policy Research in China. China Tax Publishing House, Beijing.

[7] Li, B. (2010) Macro Tax Burden, Industrial Taxes and Structural Tax Cuts. Taxation Research, No. 1. 